\title{
MAGNETIC-ACTIVATED CELL SORTING IN COMBINATION WITH SWIM-UP EFFICIENCY IMPROVE EFFECTIVITY OF SPERMATOZOA SEPARATION
}

Michal Ješeta1*, Eliska Boženková ${ }^{1}$, Jana Žáková ${ }^{1}$, Pavel Ventruba ${ }^{1}$, Igor Crha ${ }^{1}$, Eva Lousová ${ }^{1}$, Petra Coufalová ${ }^{,}$Bartosz Kempisty ${ }^{1,2,3}$

\begin{abstract}
Correct selection of spermatozoa before their using for an assisted reproductive techniques is one of the crucial step in therapy of human infertility. It was previously reported that male factor plays a major role in infertility. Basic semen analyses and standard methods for sperm selection in many cases does not eliminate sufficiently proportion of spermatozoa with genetics defects. Magnetic Activated Cell Sorting (MACS) is a selection method which reduce apoptotic sperm and improve sperm and embryo quality. The aim of our study was the comparison of swim-up method and MACS and their combination. We tested swim-up and MACS alone and treatment of spermatozoa in combination when was is first swim-up and second MACS and vice versa. In this study we evaluated sperm concentration, motility and their DNA integrity before and after separtion methods. On the basis of our results we recommend to use swim-up before MACS method. This approach brings better results in the sperm selection - lower proportion of spermatozoa with fragmented DNA and also it brings better gain of total spermatozoa usable for next IVF or ICSI methods.
\end{abstract}

Running title: Combination of MACS and swim-up

Keywords: spermatozoa, MACS, DNA integrity, swim-up, apoptosis, sperm preparation

\footnotetext{
${ }^{1}$ Department of Obstetrics and Gynecology, University Hospital and Masaryk University, Obilni trh 11, 602 00 Brno, Czech Republic

${ }^{2}$ Department of Histology and Embryology, Poznan University of Medical Sciences, Swiecickiego 6 St., 60-781 Poznan, Poland

${ }^{3}$ Department of Anatomy, Poznan University of Medical Sciences, Swiecickiego 6 St., 60-781 Poznan, Poland

* Correspondence: jeseta@gmail.com

Full list of author information is available at the end of article
} 


\section{Introduction}

Artificial fertilization techniques still do not reach the results as we wish, so there is still considerable scope for research and development in this area. Sperm selection for assisted reproductive technics (ART) in male infertility, there is currently a trend to combine multiple methods to segregate inappropriate sperm based on multiple parameters to increase the likelihood of successful fertilization. How many methods are best combined, and whether a new MACS selection method really brings a better prognosis in terms of conception success, or from the point of view of the subsequent development of the fetus, has already been studied several times. Spermatozoa selection is one of the most important step in IVF methods. The basic method of examining the quality of human sperm is the spermiogram. However, the limiting factor of the spermiogram is that the evaluation is to a certain extent subjective and depends on the experience of the embryologist. In addition, on the basis of spermiogram, about $30 \%$ of male infertility can not be detected because not all sperm damages that have a negative effect on fertilization have a microscopically clear morphological correlation [1,2]. Such damage can be, for example, fragmentation of DNA, which not only aggravates the possibility of fertilization, but if the fertilization occurs, the subsequent development of the embryo can also be negatively affected. In addition, experiments on mice have shown that such offspring may have congenital problems later on [3]. Correct selection of non-damaged sperm DNA is one of the prerequisites for achieving successful fertilization and embryo development in asssisted reproductive technologies. Data from the litarature suggest that the frequency of sperm cells with massive DNA fragmentation is a marker of sperm quality and also possible predictor of fertility [4]. Magnetic activated cell sorting (MACS) using paramagnetic Annexin V-conjugated microbeads has been proposed as a safe method to selct non-apoptotic and viable sperm. Altough many reports indicate that MACS is a beneficial technique to remove apoptotic spermatozoa and provides higher IVF outcomes compared to canonical sperm selection techniques $[5,6]$, the possible beneficial effects of this technique in clinical application are still debatable. The meta-analyses reported that MACS has possitive effect on IVF outcomes by better pregnancy rate and lower miscarriage rate [7], but in IVF donation cycles MACS method does not improve reproductive outcome [8].

The aim of our study was to compare the sperm of the conventional swim-up method with the new MACS method and also their mutual combinations to determine if MACS is really beneficial for ART and if so, how best to include it in the separation protocol.

\section{Material and methods}

\section{Evaluation of sperm concentration and motility}

The analyses of sperm concentration and motility was performed both in raw and subgrouped semen samples according WHO manual [9]. Following liquefaction for $60 \mathrm{~min}$ a semen drop $5 \mu \mathrm{l}$ was loaded onto the application area of a Makler counting chamber (Medic ring containing the counting grids was applied, and a $0.1 \mathrm{~mm}^{2}$ smear was obtained to evaluate the sperm concentration and motility. The concentration of the sample was determined by counting sperm heads in successive 10 squares. A mean was detected after counting three different 10 -square-in-rows. Motility was detected using the same chambre, counting at least 200 spermatozoa per sample and calculating the sum of motile sperm percentage. For all of these evaluations was used phase contrast microscope (Nikon, Germany) with 20x magnification.

\section{Experimental design}

For the study, a total of 11 patients were selected for different separation. Each semen sample was futher subgrouped as follows: 1) native: native ejaculate without separation 2) swim-up: only swim-up separation 3) MACS: only MACS separation 4) MACS/swim-up: after MACS separation spermatozoa were separated by swim-up 5) swim-up/MACS: imediately after swim-up methods spermatozoa were selected by MACS.

\section{Preparation of spermatozoa}

Following the liquefaction of the semen sample, the total volume in each individual subject was equally divided into four mentioned subgroups.

1) Swim-up: Pipetted semen samples in a $15 \mathrm{ml}$ conical centrifuge tube were twice 2 times washed in $2 \mathrm{ml}$ Sperm Preparation Medium (Origio, Denmark) according manufactures instruction. After second washing spermatozoa were gently overlayered with $1 \mathrm{ml}$ sperm medium (COOK, Ireland). The tube was inclined at an angle of about $45^{\circ}$, to increase to surface area of the semen-culture medium interface, and then incubated for $40 \mathrm{~min}$ at $37^{\circ} \mathrm{C}$. After gently returning the tube to upright position only $100 \mu \mathrm{l}$ from surface was collected for another analyses or appropriative spermatozoa concentartion (50 milions) was used for MACS separation.

2) MACS only: We did MACS procedure on the basic of manufacture instruction. For this technique we used MACS ${ }^{\circledR}$ GMP Annexin V Kit (Miltenyi Biotec, Germany). First step was incubation of spermatozoa with Annexin V-conjugated microbeads for 15 minutes in room temperature. Afterwards this suspension was loaded in a separation column containing iron globes, which was fitted in a magnet (MiniMACS; Milteniyi Biotec). The fraction composed of apoptotioc spermatozoa was retained in the sepa- 
ration column, and fraction with intact membranes was drained through the column and collected as non-apoptotic spermatozoa.

3) MACS/swim-up: Spermatozoa from this group were after MACS technique selected second time by swim-up method. After finishing of MACS separation spermatozoa were gently centrifuged and supernatant were discarded. Finally spermatoza swim to layer of $200 \mu \mathrm{l}$ sperm medium as described before.

4) Swim-up/MACS: After first separation of spermatozoa by swim-up were adequate number of spermatozoa (50 milions according instruction for MACS method) incubated with Annexin V-conjugated microbeads for 15 minutes. Next steps was the same as descibed before in MACS groupe.

After performing of these separation technique, spermatozoa were analysed by Halosperm method. This test is focused on nuclear DNA fragmentation.

\section{Halosperm}

Sperm DNA fragmentation was assessed with the help of the improved sperm chromatin dispersion test, known as the Halosperm G2 kit. Briefly, the semen sample was diluted to $20 \mathrm{mil} / \mathrm{ml}$ in an appropriate sperm extender. Eppendorf tubes were placed in a water bath at $90-100{ }^{\circ} \mathrm{C}$ for $5 \mathrm{~min}$ in order the agarose to be fully melted. After $5 \mathrm{~min}$ of incubation and since temperature is equilibrated at $37{ }^{\circ} \mathrm{C}$, we transfer $50 \mu \mathrm{l}$ of the diluted semen sample to the $100 \mu \mathrm{l}$ melted agarose tube and gently mixed with a pipette. Avoiding agarose solidification, we placed immediately $8 \mu \mathrm{l}$ of the cell suspension onto the sample well (provided by the kit) and we cover with a coverslip. Slides were then placed on a glass plate in the refrigerator $\left(4^{\circ} \mathrm{C}\right)$ for $5 \mathrm{~min}$ in order the agarose to be solidified with the sperm cells embedded within. After taking out the slides of the fridge, the coverslips were gently removed and the slides were placed horizontally in an elevated position. Finally we applied denaturant agent on the surface and we incubated for $7 \mathrm{~min}$. The slides afterwards were horizontally immersed in a lysis solution and incubated for 20 min. After washing with abundant distilled water for $5 \mathrm{~min}$, the slides were dehydrated in increasing concentrations of ethanol (70\% and $100 \%$ for 2 min each) and then were air-dried. For using the brightfield microscopy in this improved chromatin dispersion test, the slides were covered horizontally. Strong staining is preferred to visualise the periphery of the dispersed DNA loops halos. As provided by the ma-

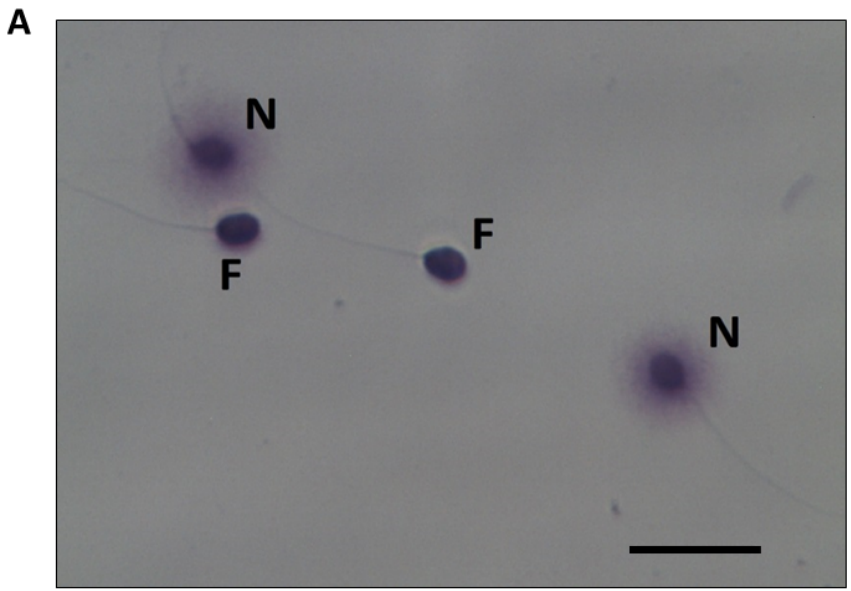

B

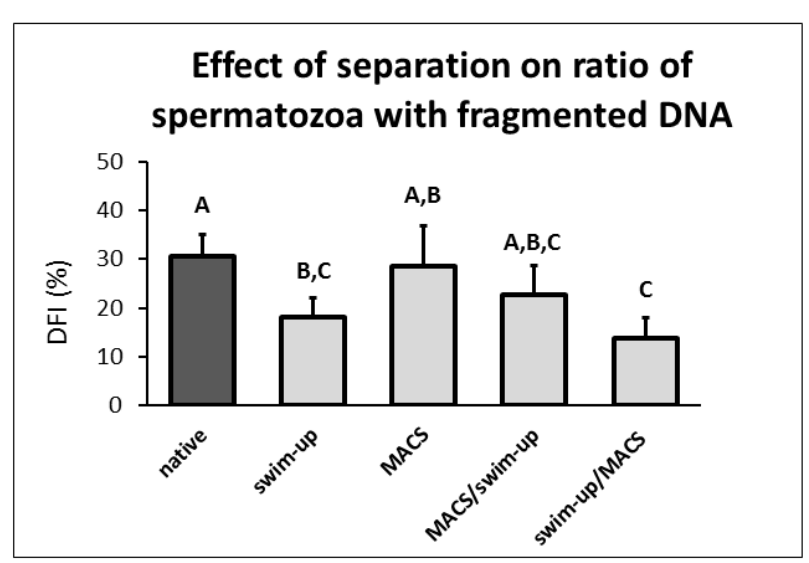

FIGURE 1 Analyses of spermatozoa for DNA integrity. A) Representative image of spermatozoa after Halosperm test, F spermatozoa with fragmented DNA, N - normal spermatozoa, scale bar represents $10 \mu \mathrm{m}$. B) Comparison of spermatozoa with fragmented DNA (expressed as DFI - DNA Fragmentation Index) before (native) and after separation. Values with different superscripts are significantly different $(A, B, C, P<0.05)$ 
nufacturer spermatozoa with big and medium halo, while spermatozoa with small, without halo and degenerated were considered to be without and with fragmentation, respectively (Fig. 1A).

The DNA fragmentation index (DFI) were calculated by the form DFI (\%) = Fragmented + Degenerated/Total cells counted. For the present study, a minimum of 500 spermatozoa per sample were scored under the x100 objective of the microscope. To reduce the bias, two different technicians counted at least 250 spermatozoa each.

\section{Statistical analysis}

STATISTICA CZ, version 10 software (StatSoft, Inc., Prague, Czech Republic). Package was used to perform the statistical analysis. Data were expressed as mean \pm standard error of the mean. Comparison of numeric variables between groups was performed using one-way analysis of variance. A P value 0.05 was considered statistically significant.

\section{Ethical approval:}

The research related to human use has been complied with all the relevant national regulations, in- stitutional policies and in accordance the tenets of the Helsinki Declaration, and has been approved by the authors' institutional review board or equivalent commitee. Ethics Committee of University Hospital Brno (Brno, Czech Republic) from 20.6.2016.

\section{Results}

Assessment of sperm concentration and motility

Compared to spermatozoa concentration in native sperm samples (average 81,4 $\mathrm{mil} / \mathrm{ml}$ ), sperm concentration significantly decreased in all other groups separation. Statisticaly significant decreasing was observed in swim-up (23,2 $\mathrm{mil} / \mathrm{ml})$, MACS $(29,6 \mathrm{mil} /$ $\mathrm{ml})$ swim-up/MACS (16,8 $\mathrm{mil} / \mathrm{ml})$ and also MACS/ swim-up $(23,4 \mathrm{mil} / \mathrm{ml})$. The application of presented methods does not bring significant changes in concentration between all selection approaches (Fig. 2A).

Total motility was significantly higher in all approaches were we used swim-up method $(92,7$ $\%)$, swim-up/MACS (84,5 \%) or MACS/swim-up $(88,1 \%)$ in compare with native ejaculate $(52,7 \%)$ and also MACS method alone $(37,8 \%)$ were detected significantly lower motility in compare to all other groups (Fig. 2B).

A

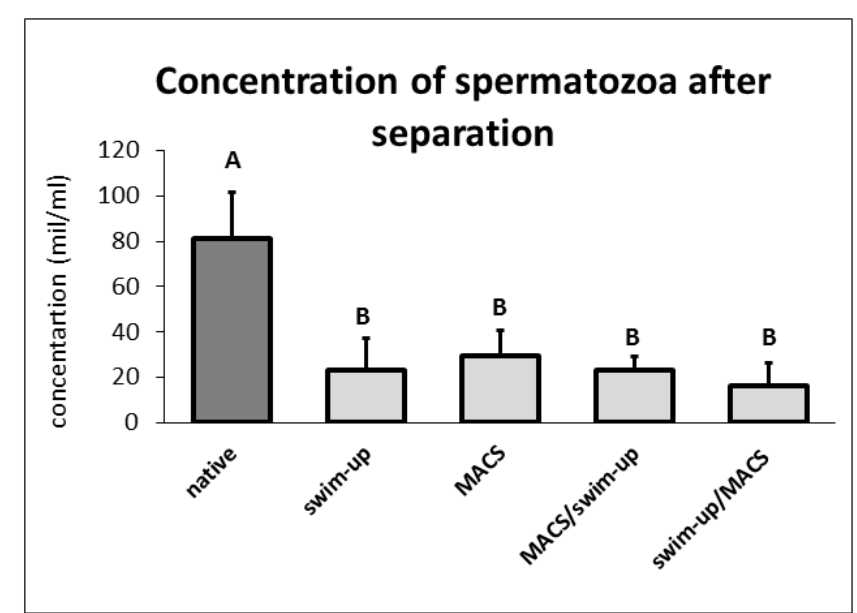

B

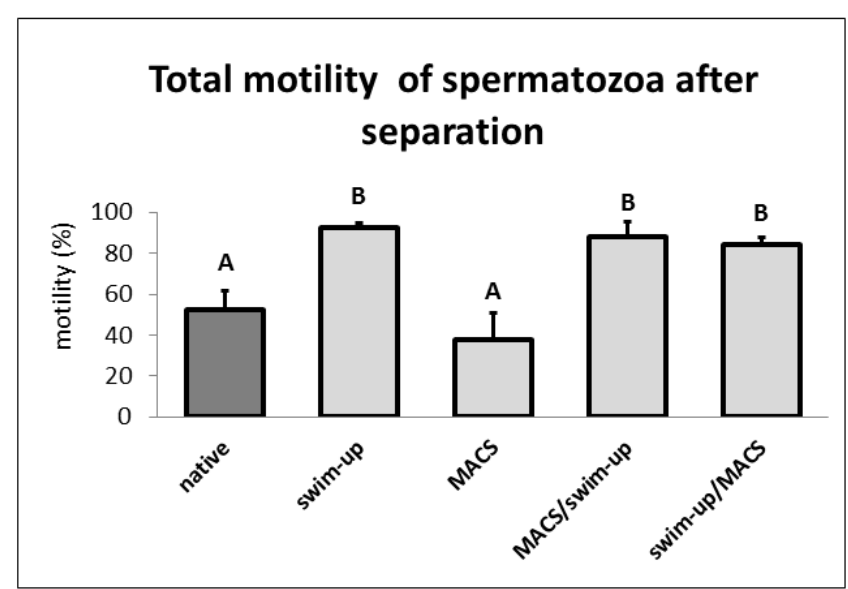

FIGURE 2 Concentration (A) and motility (B) of spermatozoa before (native) and after separation. For spermatozoa separation were used swim-up method, magnetic activated cell sorting methods (MACS) and their combination swim-up before MACS and vice versa. Values with different superscripts are significantly different $(A, B, C, P<0.05)$ 


\section{Evaluation of sperm DNA fragmentation}

The assessment of the sperm chromatin integrity was analysed by using Halosperm kit. No signifficant differnce was observed between native (DFI 30,52 $\%$ ), MACS selection (DFI 28,65 \%) and combination first MACS and second swim-up method (DFI 22,7 $\%)$. However, first swim-up and later MACS method significantly reduced proportion of spermatozoa with fragmented DNA (DFI 13,8 \%) and also suprisingly swim-up alone also significantly decreased proportion (DFI 18,2 \%) of spermatozoa with fragmented DNA in compare to native sample (Fig. 1B).

Indeed separation methods swim-up/MACS significantly decrease ratio of spermatozoa with fragmented DNA not only in compare with native ejaculate but also in comparison with MACS method.

\section{Discussion}

The present study evaluated the extent to which removing presumptive apoptotic sperm cells from samples of unselected males by means of MACS and combination with swim-up affects spermatozoa concentration, motility and DNA integrity.

There exist several studies compared the density gradient centrifugation (DGC) and MACS method, or a combination of these. Most of them concluded that, in particular, the mutual combinations of DGC and MACS are advantageous because the selected sperm have uncompromised higher viability and fewer apoptotic markers [6,10-14]. Using of MACS method significantly reduces total and progressive sperm number in compare to fresh samples [15]. It is not be considered as a problem for ICSI cycles, but it should be taken into account in the classical IVF or IUI. From our results about motility and concentration (Figure 2) we conclude, in context of limited input concentration (max 50 mil. spermatozoa), that MACS technic is not suitable for classical IVF and IUI.

In this study we presented that DFI of pre-MACS samples were sifnificantly higher than that of the post-MACS samples (Fig. 1). This results are consistent to older results articles [16]. We also observed that our results are similar to those of Tavalaee et al. [12] who also reported that for using of MACS is much better to make separation as the first step before using of MACS than after MACS. Using classic methods (swim-up or DGC) in combination with MACS is very suitable because MACS does not remove contaminating seminal plasma cells, e.g., leukocytes [10,11]. Tavalaee et al., [12] suggested that MACS before DGC is more useful for clinical sperm selection than MACS after DGC. DGC and swim-up are very freguanted systems for spermatozoa preparation. We work primary with swim-up method because it was previously reported that swim-up is, more gentle and significantly decreased proportion of fragmented spermatozoa in compare DGC [17]. The big advantage of MACS is its ability to remove apoptotic spermatozoa from sample. Some authors, however, point to a reduction in the number of progressively motile and morphologically normal sperm when using MACS, either alone or in combination $[12,15]$. Ingestion of the swim-up method before using MACS is the most effective and brings the greatest benefit to the further use of sperm in the embryology lab. MACS has limitations regarding sperm concentration and volume for loading due to the small size and volume of the column. Therefore loading raw semen into the MACS column may reduce the filtering function of MACS and impede its ability to isolate motile non-apoptotic sperm, because dead/apoptotic sperm bind to the MACS column in competition with motile/non-apoptotic sperm.

Some studies have seen a higher level of fertilization when using MACS $[14,18]$ and other statistically significant differences do not confirm their use [1921]. For explanation of this controversial results is very important age and reproductive status donors of fertilized oocytes. It was reported that sperm DNA fragmentation affects the pregnancy rate negatively and is caused by both male factor (DNA damage) and female factor (inability to repair DNA) [8]. Studies that tracked the number of pregnancies occurred showed their higher frequency when the MACS method was included in the selection protocol [19$21]$, but in case of donation cycles was not observed any positive effect [8].

\section{Conclusions}

Our study shows that it is appropriate to use swim-up separation before the MACS method. This approach is effective and can be advantageously used in the selection of sperm for assisted reproduction methods. Especially because it increases the proportion of non-apoptotic sperm, although at the expense of the overall reduction in the number of motile sperm.

\section{Acknowledgements}

Publication of this article was made possible by grant MH CZ - DRO (FNBr, 65269705), project MSMT LTC 18059 and fund from the Faculty of Medicine MU to junior researcher Michal Jeseta

\section{Corresponding author}

Ing. Ješeta Michal, Ph.D., Department of Obstetrics and Gynecology, University Hospital and Masaryk University, Obilni trh 11, 60200 Brno, Czech Republic, e-mail: jeseta@gmail.com

\section{Conflict of interest statement}

The authors declare they have no conflict of interest

\section{References}

1. Evenson DP, Larson KL, Jost LK. Sperm chromatin structure andrology lab corner assay: its clinical use for detecting sperm DNA fragmentation in male infertility and comparisons with other techniques. J Androl. 2002;23(1):25-43; DOI:10.1002/j.1939-4640.2002.tb02599.x.

2. Lewis SE, Aitken RJ, Conner SJ, Iuliis GD, Henkel R, Giwercman A, Gharagozloo $P$. The impact of sperm DNA damage in assisted conception and beyond: recent advances in diagnosis and treatment. Reprod Biomed. 2013;27(4):325-37; DOI:10.1016/j.rbmo.2013.06.014.

3. Ramos-Ibeas P, Calle A, Fernández-González R, Laguna-Barraza R, Pericuesta E, Calero A, Ramíréz MA, Gutiérrez-Adán A. Intracytoplasmic sperm injection using DNA fragmented sperm in mice negatively affects embryo-derived embryonic stem cells, reduces the fertility of 
male offspring and induces heritable changes in epialleles. PLoS ONE. 2014;9:e95625; DOI:10.1371/journal.pone.0095625.

4. Bungum M, Humaidan P, Axmon A, Spano M, Bungum L, Erenpreiss J, Giwercman A. Sperm DNA integrity assessment in prediction of assisted reproduction technology outcome. Hum Reprod. 2007;22(1):174-9; DOI:10.1093/humrep/del326.

5. Huang C, Lee T, Chen C, Wu G, Lee C, Lee M. Sperm preparation by magnetic-activated cell sorting improve the sperm zona pellucida binding capacity and reduces apoptotic sperm. Hum Repro. 2009;24 Suppl 1:2147-218.

6. Young Obejero E, De Caro R, Marconi G, Lomardi E, Young E, Tiveron M, Valcarcel A. Reproductive outcome using Annexin V columns for nonapoptotic sperm selection. Hum Reprod. 2010;25 Suppl 1:6-9.

7. Zhao J, Zhang Q Wang Y, Li Y. Whether sperm deoxyribonucleic acid fragmentation has an effect on pregnancy and miscarriage after in vitro fertilization/intracytoplasmic sperm injection: a systematic review and meta-analyses. Fertil Steril. 2014;102(4):998-1005; DOI:10.1016/j. fertnstert.2014.06.033.

8. Romany L, Garrido N, Motato Y, Belén A, Remohí J, Meseguer M. Removal of annexin $\mathrm{V}$ - positive cells for intracytoplasmic sperm injection in ovum donation cycles does not improve reproductive outcome: a controlled and randomized trial in unselected males. Fertil Steril. 2014;102(6):1567-75; DOI:10.1016/j.fertnstert.2014.09.001

9. World Health Organization. Semen analysis. In WHO laboratory manual for the Examination and processing of human semen. Fift ed., WHO Press, World Health Organization, 20 Avenue Appia, 1211 Geneva 27 Switzerland World Health Organization; 2010. p. 7-114.

10. Said TM, Grunewald S, Paasch U, Glander HJ, Baumann T, Kriegel C, Li L Agarwal A. Advantage of combining magnetic cell separation with sperm preparation techniques. Reprod Biomed Online. 2005a;10(ž):740-6; DOI:10.1016/S1472-6483(10)61118-2.

11. Said TM, Grunewald S, Paasch U, Rasch U, Agarwal A, Glander HJ. Effects of magnetic-activated cell sorting on sperm motility and cryosurvival rates. Fertil Steril. 2005b;83(5):1442-6; DOI:10.1016/j fertnstert.2004.11.052.

12. Tavalaee M, Deemeh, MR., Arbabian M, Nasr-Esfahani, MH. Density gradient centrifugation before or after magnetic-activated cell sorting which technique is more useful for clinical sperm selection? J Assist Reprod Genet. 2012;29(1):31-8; DOI:10.1007/s10815-011-9686-6.

13. De Vantéry Arrighi C, Hervé L, Chardonnens D, Agostini A. Removal of spermatozoa with externalized phosphatidylserine from sperm preparation in human assisted medical procreation: effects on viability, motility and mitochondrial membrane potential. Reprod Biol Endocrinol 2009;7:1-12; DOI:10.1186/1477-7827-7-1.

14. Romany L, Meseguer M, García-Herrero S, Garrido N. Magnetic activated sorting of non-apoptotic sperm result in improved embryo quality in ovum donation cycles with intracytoplasmic sperm injection. Hum Reprod. 2010;25 Suppl 1:8.

15. Cakar Z, Cetinkaya B, Aras D, Ozkavukcu S, Kaplanoglu I, Cinar O. Does combining magnetic-activated cell sorting with density gradient or swim-up improve sperm selection? J Assist Reprod Genet 2016;33(8):1059-65; DOI:10.1007/s10815-016-0742-0.

16. Chi HJ, Kwak SJ, Kim SG, Kim YY, Park JY, Yoo ChS, Park IH, Sun HG, Kim JW, Lee KH. Efficient isolation of sperm with high DNA integrity and stable chromatin packaging by a combination of density-gradient centrifugation and magnetic.activated cell sorting. Clin Exp Reprod Med. 2016;43(4):199-206; DOI:10.5653/cerm.2016.43.4.199.

17. Zini A, Finelli A, Phang D, Jarvi K. Influence of semen processing technique on human sperm DNA integrity. Urology. 2000;56(6):1081-4.

18. Grunewald S, Reinhardt M, Blumenauer V, Sai TM, Agarwal A, Abu Hmeidan F, Glander HJ, Paasch U. Increased sperm chromatin decondensation in selected nonapoptotic spermatozoa of patients with male infertility. Fertil Steril. 2009;92 (2):572-77; DOI:10.1016/j. fertnstert.2008.07.1705

19. Alvares Sedó C, Uriondo H, Lavolpe M, Noblia F, Papier S, Nodar F. Clinical outcome using non-apoptotic sperm selection for ICSI procedures: report of 1 year experience. Fertil Steril. 2010;94(4):S232; DOI:10.1016/j fertnstert.2010.07.902.

20. Buzzi J, Valcarcel A, Lombardi E, Oses R, Rawe V, Young E. Magnetic activated cell sorting (MACS) improves oocyte donation results associated to severe male factor infertility. Hum Reprod. 2010;25 Suppl 1:118-52.

21. Dirican EK, Özgün OD, Akarsu S, Akin KO, Ercan O, Ugurlu M, Camsari C, Kanyilmaz O, Kaya A, Unsal A. Clinical outcome of magnetic activated cell sorting of nonapoptotic spermatozoa before density gradient centrifugation for assisted reproduction. J Assist Reprod Genet. 2008;25(8):375-81; DOI:10.1007/s10815-008-9250-1. 